\title{
Article \\ Sport in Town: The Smart Healthy ENV Project, a Pilot Study of Physical Activity with Multiparametric Monitoring
}

\author{
Marco Laurino ${ }^{1, *(\mathbb{C})}$, Tommaso Lomonaco ${ }^{2}\left(\mathbb{D}\right.$, Francesca Giuseppa Bellagambi ${ }^{3}{ }^{\circ}$, Silvia Ghimenti ${ }^{2}$, \\ Alessandro Messeri ${ }^{4,5}{ }^{\mathbb{D}}$, Marco Morabito ${ }^{4,5}$, Elena Marrucci ${ }^{1}$, Lorenza Pratali ${ }^{1}$ and Maria Giovanna Trivella ${ }^{1}$ \\ 1 Institute of Clinical Physiology, National Research Council, 56124 Pisa, Italy; \\ e.marrucci1@studenti.unipi.it (E.M.); lorenza@ifc.cnr.it (L.P.); trivella@ifc.cnr.it (M.G.T.) \\ 2 Department of Chemistry and Industrial Chemistry, University of Pisa, 56124 Pisa, Italy; \\ tommaso.lomonaco@unipi.it (T.L.); silvia.ghimenti@unipi.it (S.G.) \\ 3 Institute of Analytical Sciences, University of Claude Bernard Lyon 1, Villeurbanne, 69100 Lyon, France; \\ francesca.bellagambi@univ-lyon1.fr \\ 4 Institute of Bioeconomy, National Research Council (IBE-CNR), 50019 Florence, Italy; \\ alessandro.messeri@unifi.it (A.M.); marco.morabito@ibe.cnr.it (M.M.) \\ 5 Centre of Bioclimatology, University of Florence (UNIFI), 50144 Florence, Italy \\ * Correspondence: laurino@ifc.cnr.it
}

check for updates

Citation: Laurino, M.; Lomonaco, T.; Bellagambi, F.G.; Ghimenti, S.; Messeri, A.; Morabito, M.; Marrucci, E.; Pratali, L.; Trivella, M.G. Sport in Town: The Smart Healthy ENV Project, a Pilot Study of Physical Activity with Multiparametric Monitoring. Int. J. Environ. Res. Public Health 2021, 18, 2432. https:// doi.org/10.3390/ijerph18052432

Academic Editor: Jaime Hart

Received: 20 January 2021

Accepted: 26 February 2021

Published: 2 March 2021

Publisher's Note: MDPI stays neutral with regard to jurisdictional claims in published maps and institutional affiliations.

Copyright: (c) 2021 by the authors. Licensee MDPI, Basel, Switzerland. This article is an open access article distributed under the terms and conditions of the Creative Commons Attribution (CC BY) license (https:// creativecommons.org/licenses/by/ $4.0 /)$
Abstract: Background: Increasing evidence links meteorological characteristics and air pollution to physiological responses during sports activities in urban areas with different traffic levels. Objective: The main objective of the Smart Healthy ENV (SHE, "Smart Monitoring Integrated System For A Healthy Urban Environment In Smart Cities") project was to identify the specific responses of a group of volunteers during physical activity, by monitoring their heart rates and collecting breath samples, combined with data on meteorological determinants and pollution substances obtained through fixed sensor nodes placed along city routes and remotely connected to a dedicated data acquisition server. Methods: Monitoring stations were placed along two urban routes in Pisa, each two km long, with one located within the park beside the Arno river (green route) and the other in a crowded traffic zone (red route). Our sample participants were engaged in sports activities ( $N=15$, with different levels of ability) and were monitored through wearable sensors. They were first asked to walk back and forth $(4 \mathrm{~km})$ and then to run the same route. The experimental sessions were conducted over one day per route. A breath sample was also collected before each test. A questionnaire concerning temperature and fatigue perception was administered for all of the steps of the study over the two days. Results: The heart rates of the participants were monitored in the baseline condition, during walking, and while running, and were correlated with meteorological and pollutant data and with breath composition. Changes in the heart rates and breath composition were detected during the experimental sessions. These variations were related to the physical activity and to the meteorological conditions and air pollution levels. Conclusions: The SHE project can be considered a proof-of-concept study aimed at monitoring physiological and environmental variables during physical activity in urban areas, and can be used in future studies to provide useful information to those involved in sports and the broader community.

Keywords: sport; multiparametric monitoring; air pollution; heat stress; microclimate determinants; heart rate; breath; physical activity

\section{Introduction}

As stated by the European Environment Agency, "A clean environment is essential for human health and well-being. At the same time, the local environment can also be a source of stressors - for example air pollution, noise, hazardous chemicals - that negatively affect health." The interactions between the environment and human health are highly complex and difficult to assess. Numerous environmental variables (such as ambient air pollution, 
poor water quality, and insufficient sanitation) are expected to affect outdoor physical activity (OPA) [1]. Chronic diseases are also known to be closely linked to unhealthy lifestyles. OPA can have direct health benefits, improving mental and physical wellbeing and health-related quality of life, and long-term adherence to physical activity is healthier for individuals [2-4]. Physical activity can be conducted in both city streets and urban parks and trails, which we refer to as "urban red areas" (URAs) and "urban green areas" (UGAs), respectively. UGAs enable a wide range of free or low-cost activities (both training and recreational), based on environmental factors that are frequently linked to increased levels of OPA $[5,6]$. In URAs, ambient fine particulate matter $\left(\mathrm{PM}_{2.5}\right)$ and household air pollution from solid fuel combustion have been identified as risk factors that have negative effects on human health, similar to those reported for other habits such as smoking and drinking alcohol $[7,8]$. The effects of increased levels of air pollution on athletic performance have been measured using physiological parameters. In 2001, Carlisle and Sharp examined the effects of major pollutants on human health in terms of exercise [9]. They suggested that physical activity should not be conducted during rush hour, in order to minimize exposure to high levels of nitrogen oxides $\left(\mathrm{NO}_{\mathrm{x}}\right)$, carbon monoxide $(\mathrm{CO})$, and volatile organic compounds (VOCs). These pollutants are likely to accumulate in the environment and thus may affect athletic performance. In addition, OPA is not recommended if ozone $\left(\mathrm{O}_{3}\right)$ levels are high, as this results in a significant decrease in lung function [10,11]. Ambient levels of sulfur dioxide $\left(\mathrm{SO}_{2}\right)$ can also be a significant irritant for asthmatics [11].

The cardiovascular benefits of exercise are well established. Exercising regularly reduces the risk of adverse cardiovascular events and can act as a multifunctional intervention tool for prevention, due to its effects on multiple biochemical pathways, unlike conventional drug therapy [12]. In particular, exercise training is an important additional type of non-pharmacological treatment for patients suffering from heart failure (HF), and has proven positive effects on mortality, morbidity, exercise capacity, and quality of life [13]. This implies that the OPA conducted in urban areas by amateurs, athletes, or those suffering from respiratory and heart diseases (such as HF), bears a risk of adverse effects from environmental pollution. Thus, the environmental monitoring of pollution in urban areas, both in terms of environmental variables (i.e., humidity and temperature) and pollutants (i.e., chemical air pollutants), should be conducted [14-17]. A multiparametric approach can provide information about both pollution levels and physical activity, thus helping those conducting OPA to select the most suitable days and the best urban areas, along with personalizing their training programs. Physical activity monitoring can be conducted through exhaled breath analysis, as the chemical composition of human breath samples enables relevant information about ongoing physiological processes to be obtained non-invasively [18-20]. During a typical respiratory cycle, several endogenous and exogenous VOCs are generally exchanged within the upper and lower respiratory tract, meaning that breath analysis is an effective approach to monitoring human exposure to environmental pollutants and health status [21]. The main advantage of this approach is the use of non-invasive collection procedures, as unlike blood collection they do not require trained personnel [22]. Breath acetone and isoprene are potentially useful indicators of the $\beta$-oxidation of fatty acids and of cardiac output, respectively [23].

This paper presents a proof-of-concept study involving the multi-parametric monitoring of healthy volunteers conducting OPA in urban areas, together with remotely acquired environmental variables. This can be regarded as the first step in a future plan for smart cities [24], and represents a starting point for examining the links between human health, physical activities, and environmental pollution, which can then be investigated in further detail with a larger sample.

Environmental conditions can have specific effects on different people, so the aim of this study is to lay the foundation for a personalized multi-parametric monitoring approach and the design of personalized training programs, by examining the responses of individuals with different health statuses and fitness levels. Thus, the main objectives of this study are to: 
- $\quad$ Build a dedicated system to monitor environmental conditions (meteorological and pollution conditions) in different urban areas and individual physiological parameters during outdoor physical activity;

- Develop a pilot feasibility study for evaluating the impact of pollution and microclimatic variables on the populace.

\section{Materials and Methods}

Two routes were identified (A and B) in the city of Pisa. A "green route" was selected along the Arno river in an area characterized by extensive vegetation and limited vehicular traffic, and a busier "red route" was located along a high traffic-volume road artery (see Figure 1). Each route was approximately $4 \mathrm{~km}$ (round trip).

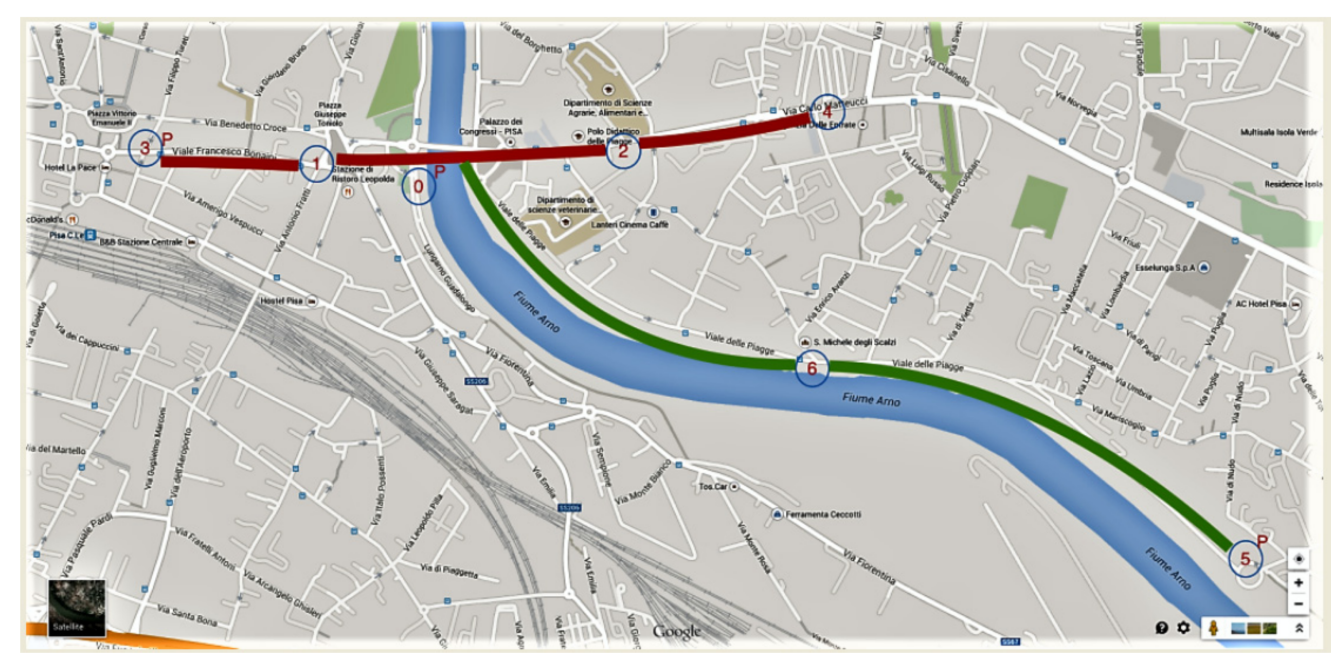

Figure 1. Fixed sensor nodes along the Arno River green park (green route) and along a crowded traffic zone (red route). Five nodes were positioned on the red route (nodes $0,1,2,3$, and 4). Node 0 was also on the green route, where two additional nodes were positioned (nodes 5-6).

Fixed sensor nodes were placed in both these "urban environment" sectors to acquire meteorological and air pollution parameters and to collect air quality and thermal stress indicators.

Each fixed node can detect the concentrations of atmospheric pollutants typical of urban environments, such as $\mathrm{CO}$, carbon dioxide $\left(\mathrm{CO}_{2}\right), \mathrm{O}_{3}$, and unburned hydrocarbons (HC), in addition to micro-meteorological parameters (i.e., air temperature, relative humidity, atmospheric pressure, wind speed, and black globe temperature). Some nodes also have a module for the detection of fine dust $\left(\mathrm{PM}_{2.5}\right)$. The micro-meteorological parameters collected by the nodes enable the calculation of the wet-bulb globe temperature (WBGT) $[25,26]$ and the universal thermal climate index (UTCI) $[27,28]$, which can be used to evaluate the thermal environment and in particular the potential thermal discomfort to which the subjects were exposed during the tests.

The environmental and meteorological data were temporally matched with the physiological variables (heart rate changes) obtained by wearable sensors (WINPack system, Medical Equipment marked CE0434 according to 93/42/EEC directive, Medical Device Class IIA) and the chemical composition of the breath samples was collected before and after walking and running, for both the A and B paths. The wearable sensors of the WINPack enable the monitoring of multiple physiological parameters through different modules and include a rechargeable battery and a Bluetooth communication system, four leads, an electrocardiogram cable, a body position monitor, and a three-axial accelerometer module for measuring physical activity. The recorded data were post-processed and analyzed on a dedicated console by medical doctors, with the temporal matching of the environmental data acquired using a dedicated server (see Supplementary File S1 "ICT infrastructure"). 
A questionnaire concerning temperature perception and fatigue was administered to the participants for all of the steps of the study (before the test, after walking, and after running) on both days. This was used to capture their subjective evaluations of physical fatigue, respiratory distress (difficulty in breathing), tachycardia, and possible thermal discomfort (see the Supplementary File S2 "Questionnaire").

The protocol was approved by the North West Area Ethics Committee of the Tuscany Region (CEAVNO, Autonomous Section of the Regional Ethics Committee for Clinical Trials, Resolution AOUP 838/2013).

A small group of healthy volunteers was enrolled $(N=15)$. Each participant gave their informed consent. The data of the subjects enrolled were added to a specifically constructed database, which was managed exclusively by the medical researchers participating in the project.

The wearable sensors were positioned on the volunteers in an ambulatory room. After uploading the demographic data and checking the electrocardiogram (EKG) trace on the console, the volunteers (usually two) were accompanied to the chosen urban area on the first day (the same procedure was repeated on the second day in the other zone) to embark on the walking and running activities.

At the test site, the volunteers were asked to fill a custom-made Nalophan bag (Figure 2) so we could collect an exhaled breath sample. The Nalophan bag $(50 \mathrm{~cm} \times 23.5 \mathrm{~cm}$, surface-to-volume ratio of $0.6 \mathrm{~cm}^{-1}$ ) was made from a roll of polyethylene terephthalate tube (diameter $23.5 \mathrm{~cm}$, film thickness $20 \mu \mathrm{m}$ ) supplied by Kalle (Germany) according to the procedure described elsewhere [29].

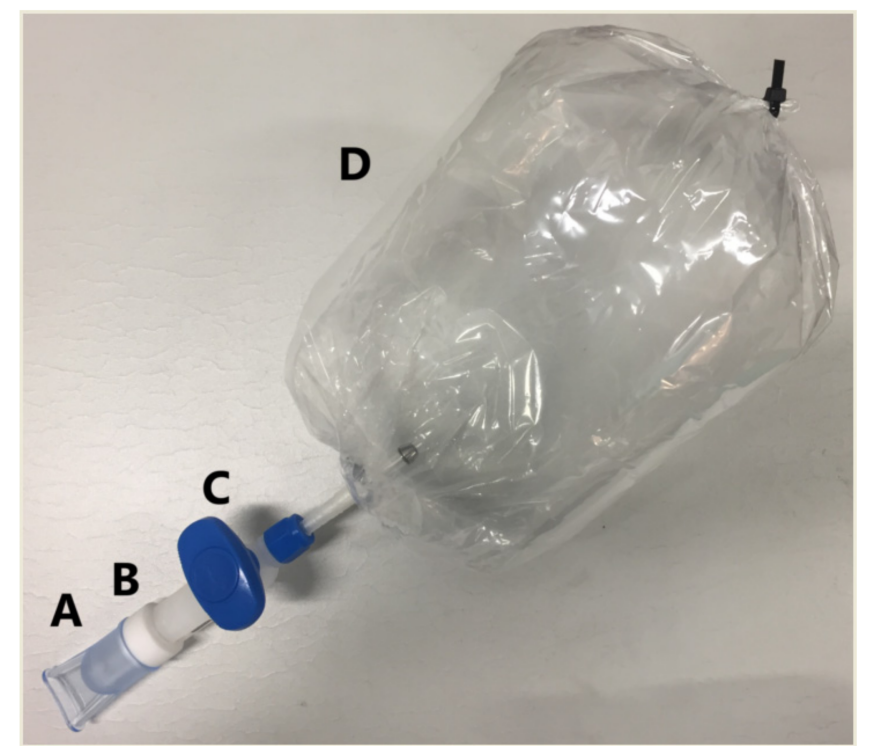

Figure 2. Breath sampling system composed of (A) disposable mouthpiece, (B) non-return valve, (C) two-way valve, and (D) Nalophan bag.

A solid-phase extraction (SPE) technique was used to extract analytes from the breath samples. The analysis was conducted using a thermal desorption unit combined with a gas-chromatography and mass spectrometry (TD-GC-MS) procedure, as described elsewhere [30]. At the end of the test, the wearable sensors were removed so the acquired signal could be downloaded to the console for subsequent storage and analysis.

The correlations between the heart rate data (considering the RR interval, i.e., the time elapsed between two successive R-waves of the EKG signal) and the climate/pollutant data were statistically evaluated using non-parametric tests (paired Spearman rank correlations). To evaluate the effects of the run/walk conditions and red/green routes, we obtained correlations by separately considering the data collected in the four conditions. The data collected through questionnaires concerning temperature perception and fatigue were 
analyzed using repeated-measures ANOVAs (rANOVAs). The questionnaire data collected after walking ( $\mathrm{t} 1$ ) and running ( $\mathrm{t} 2$ ) for both the red and green routes were considered as variables in the rANOVAs, normalized with data collected before walking and running (t0). A main time effect (2 levels: "t1- $\mathrm{t} 0$," which is the normalized post-walk, and " $\mathrm{t} 2-\mathrm{t} 0$," which is the normalized post-run) and a route effect (2 levels: red or green) were considered as within-factors in the rANOVA.

\section{Results}

The Smart Healthy ENV (SHE) pilot study was conducted on a group of 15 healthy volunteers (age: 31 to 57 years old, mean age $=43$ years old; six females and nine males; BMI: 19.6 to $27.0 \mathrm{~kg} / \mathrm{m}^{2}$; mean BMI $=22.7 \mathrm{~kg} / \mathrm{m}^{2}$ ), before and during four tests: walking along the green route, running along the green route, walking along the red route, and running along the red route. The experimental sessions were performed over nine days in 2017, from May to July.

Table 1 reports the demographic data and heart rate values of the enrolled population collected before and during the tests for both the A and B routes. Detailed information regarding each subject's profession, training practice, smoking habits, and temperature and fatigue perception before and after each test were collected (see Supplementary File S3: "Subject Features" and File S4 "Questionnaire Data and Analysis").

Table 1. Demographic data and heart rate values measured before walking $\left(\mathrm{HR}_{\mathrm{b}}\right)$ and before running $\left(\mathrm{HR}_{\mathrm{pr}}\right)$ for both green and red routes. Note: $\mathrm{HR}^{\max }{ }_{\mathrm{w}}$ and $\mathrm{HR}^{\max }{ }_{\mathrm{r}}$ are the maximum values reached during walking and running, respectively.

\begin{tabular}{|c|c|c|c|c|c|c|c|c|c|c|c|}
\hline \multirow{2}{*}{ ID } & \multirow{2}{*}{ Gender } & \multirow{2}{*}{$\begin{array}{l}\text { Age } \\
\text { (Year) }\end{array}$} & \multirow{2}{*}{$\begin{array}{c}\text { BMI } \\
\left(\mathrm{kg} / \mathrm{m}^{2}\right)\end{array}$} & \multicolumn{4}{|c|}{ Green Route } & \multicolumn{4}{|c|}{ Red Route } \\
\hline & & & & $\mathrm{HR}_{\mathrm{b}}$ & $\mathrm{HR}^{\max }{ }_{\mathrm{w}}$ & $\mathrm{HR}_{\mathrm{pr}}$ & $\mathrm{HR}^{\max }{ }_{\mathrm{r}}$ & $\mathrm{HR}_{\mathrm{b}}$ & $\mathrm{HR}^{\max }{ }_{\mathrm{w}}$ & $\mathrm{HR}_{\mathrm{pr}}$ & $\mathrm{HR}^{\max }{ }_{r}$ \\
\hline N01 & M & 46 & 22.4 & 50 & 67 & 51 & 150 & 56 & 60 & 50 & 120 \\
\hline N02 & $\mathrm{M}$ & 39 & 22.2 & 65 & 70 & 68 & 162 & 64 & 67 & 65 & 150 \\
\hline N03 & M & 52 & 21.5 & 50 & 77 & 63 & 127 & 60 & 90 & 64 & 142 \\
\hline N04 & M & 44 & 21.5 & 63 & 82 & 67 & 155 & 60 & 90 & 65 & 127 \\
\hline N05 & $\mathrm{F}$ & 39 & 20.5 & 63 & 72 & 60 & 180 & 64 & 70 & 65 & 170 \\
\hline N06 & $\mathrm{F}$ & 49 & 20.7 & 74 & 90 & 75 & 120 & 77 & 105 & 80 & 170 \\
\hline N07 & $\mathrm{M}$ & 32 & 25.1 & 80 & 90 & 75 & 195 & 71 & 88 & 70 & 195 \\
\hline N08 & M & 32 & 27.0 & 50 & 78 & 71 & 140 & 54 & 75 & 61 & 170 \\
\hline N09 & M & 32 & 26.1 & 107 & 110 & 105 & 127 & 105 & 108 & 103 & 120 \\
\hline N10 & $\mathrm{F}$ & 57 & 19.6 & 64 & 100 & 80 & 172 & 85 & 115 & 94 & 180 \\
\hline N11 & F & 50 & 21.6 & 67 & 90 & 66 & 177 & 67 & 90 & 67 & 165 \\
\hline N12 & $F$ & 37 & 23.5 & 80 & 105 & 84 & 172 & 86 & 112 & 80 & 180 \\
\hline N13 & $\mathrm{F}$ & 52 & 21.6 & 85 & 97 & 90 & 168 & 80 & 97 & 78 & 180 \\
\hline N14 & $\mathrm{M}$ & 31 & 24.7 & 75 & 85 & 75 & 172 & 77 & 82 & 52 & 160 \\
\hline N15 & M & 52 & 22.3 & 67 & 72 & 63 & 150 & 65 & 70 & 68 & 152 \\
\hline
\end{tabular}

The instrumentation used in this pilot study enabled physiological data to be effectively collected during all of the tests. Figure 3 shows the electrocardiogram of a physically fit volunteer recorded during walking (panel A) and during running (panel B) along the green route.

The environmental sensor nodes were able to detect concentrations of $\mathrm{CO}, \mathrm{CO}_{2}$, $\mathrm{HC}, \mathrm{O}_{3}$, and $\mathrm{PM}_{2.5}$. The WBGT index and UTCI values were also estimated using the micro-meteorological parameters collected by each node. 
A)

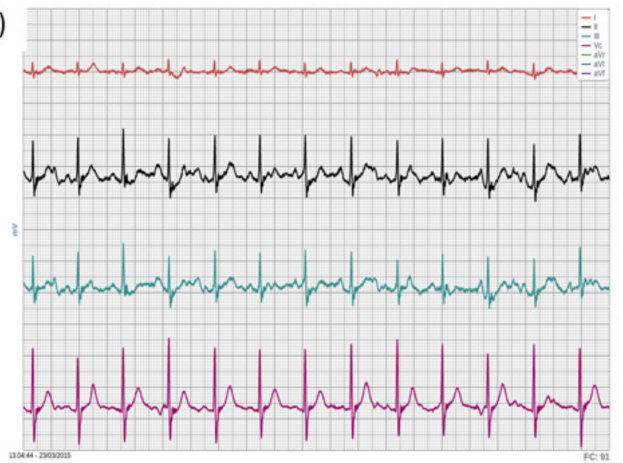

B)

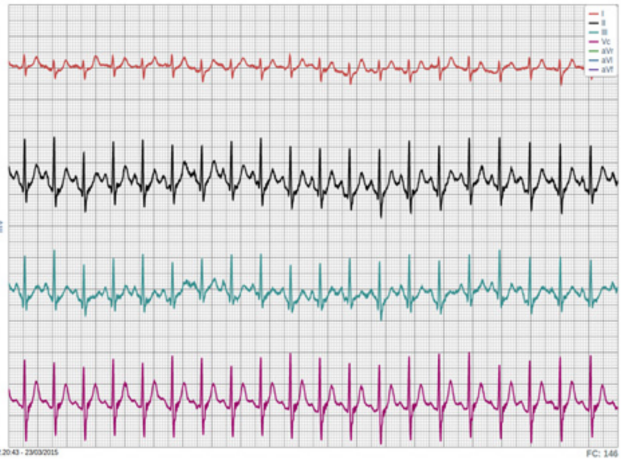

Figure 3. Typical examples of EKG monitored during walking (A) and running (B).

The average values for each of the environmental and pollutant parameters were monitored and collected during the days of the field tests, and the parameters recorded for each subject when running and walking are shown in Table 2.

Table 2. Mean values of environmental parameters collected by the nodes during the tests for each experimental session of green and red routes. Route: $\mathrm{R}=$ red, $\mathrm{G}=$ green; $\mathrm{WS}=$ wind speed $(\mathrm{m} / \mathrm{s}) ; \mathrm{T}=$ temperature $\left({ }^{\circ} \mathrm{C}\right) ; \mathrm{RH}=$ relative humidity $(\%) ; \mathrm{P}=$ atmospheric pressure $(\mathrm{hPa}) ; \mathrm{CO}=$ carbon monoxide $(\mathrm{ppm}) ; \mathrm{CO}_{2}=$ carbon dioxide $(\mathrm{ppm}) ; \mathrm{HC}=\mathrm{hydrocarbons}$ $(\mathrm{ppm}) ; \mathrm{O}_{3}=$ ozone $(\mathrm{ppb}) ; \mathrm{PM}_{2.5}=$ particulate matter $\left(\mathrm{ug} / \mathrm{m}^{3}\right) ; \mathrm{Rmed}=$ average solar radiation $\left(\mathrm{W} / \mathrm{m}^{2}\right) ; \mathrm{Rmax}=\operatorname{maximum}$ solar radiation $\left(\mathrm{W} / \mathrm{m}^{2}\right)$; WBGTmed = average wet bulb globe temperature $\left({ }^{\circ} \mathrm{C}\right)$; WBGTmax = maximum wet bulb globe temperature $\left({ }^{\circ} \mathrm{C}\right)$; UTCImed $=$ average universal thermal climate index $\left({ }^{\circ} \mathrm{C}\right)$; UTCImax $=$ maximum universal thermal climate index $\left({ }^{\circ} \mathrm{C}\right)$. MD: missing data.

\begin{tabular}{|c|c|c|c|c|c|c|c|c|c|c|c|c|c|c|c|c|}
\hline \multicolumn{17}{|c|}{ Walk } \\
\hline Route & Date & WS & $\mathrm{T}$ & RH & $\mathbf{P}$ & $\mathrm{CO}$ & $\mathrm{CO}_{2}$ & HC & $\mathrm{O}_{3}$ & $\mathbf{P M}_{2.5}$ & $\begin{array}{c}\mathbf{R} \\
\text { Med }\end{array}$ & $\begin{array}{c}\mathbf{R} \\
\text { Max }\end{array}$ & $\begin{array}{c}\text { WBGT } \\
\text { Med }\end{array}$ & $\begin{array}{l}\text { UTCI } \\
\text { Med }\end{array}$ & $\begin{array}{l}\text { WBGT } \\
\text { Max }\end{array}$ & $\begin{array}{l}\text { UTCI } \\
\text { Max }\end{array}$ \\
\hline $\mathbf{R}$ & 3 May & 1.1 & 15.1 & 76 & 1018 & 2.6 & 380 & 3.1 & 40.9 & MD & 450 & 585 & 16.1 & 23.5 & 17.0 & 26.0 \\
\hline $\mathbf{R}$ & 5 May & 1.9 & 16.3 & 82 & 1020 & 2.5 & 415 & 6.3 & 42.2 & 18.5 & 450 & 605 & 17.1 & 23.0 & 17.9 & 25.9 \\
\hline G & 1 June & 1.1 & 23.5 & 58 & 1019 & 1.7 & 363 & 4.0 & 49.7 & 14.5 & 542 & 756 & 22.8 & 31.7 & 24.2 & 34.6 \\
\hline G & 6 June & 1.3 & 22.9 & 67 & 1008 & 1.9 & 362 & 4.1 & 51.0 & 3.8 & 334 & 535 & 21.7 & 28.0 & 22.8 & 31.2 \\
\hline $\mathbf{R}$ & 7 June & 2.0 & 21.7 & 54 & 1012 & 1.8 & 400 & 3.9 & 27.2 & 4.6 & 510 & 689 & 19.8 & 27.5 & 20.7 & 30.3 \\
\hline G & 21 June & 0.8 & 26.9 & 59 & 1016 & 1.6 & 345 & 5.0 & 48.3 & 5.7 & 491 & 651 & 25.8 & 34.5 & 26.9 & 36.6 \\
\hline $\mathbf{R}$ & 23 June & 2.3 & 27.0 & 67 & 1018 & 1.4 & 419 & 4.0 & 37.9 & 10.0 & 453 & 638 & 25.5 & 32.6 & 26.3 & 35.1 \\
\hline G & 7 July & 0.7 & 27.7 & 46 & 1018 & 1.6 & 361 & 4.3 & 58.7 & 3.0 & 446 & 600 & 25.0 & 33.8 & 26.1 & 35.9 \\
\hline $\mathbf{R}$ & 14 July & 1.3 & 27.6 & 72 & 1009 & 1.2 & 314 & 4.4 & 41.3 & 12.3 & 434 & 595 & 27.0 & 35.0 & 27.9 & 37.1 \\
\hline \multicolumn{17}{|c|}{ Run } \\
\hline Route & Date & WS & $\mathrm{T}$ & RH & $\mathbf{P}$ & $\mathrm{CO}$ & $\mathrm{CO}_{2}$ & HC & $\mathrm{O}_{3}$ & $\mathbf{P M}_{2.5}$ & Rmed & $R \max$ & $\begin{array}{l}\text { WBGT } \\
\text { Med }\end{array}$ & $\begin{array}{l}\text { UTCI } \\
\text { Med }\end{array}$ & $\begin{array}{l}\text { WBGT } \\
\text { Max }\end{array}$ & $\begin{array}{l}\text { UTCI } \\
\text { Max }\end{array}$ \\
\hline $\mathbf{R}$ & 3 May & 0.8 & 16 & 72 & 1019 & 2.2 & 418 & 3.8 & 38.7 & MD & 830 & 1072 & 20 & 30.3 & 21.7 & 33.8 \\
\hline $\mathbf{R}$ & 5 May & 1.9 & 17.4 & 73 & 1021 & 2.8 & 420 & 6.6 & 41.2 & 14.5 & 786 & 944 & 19.2 & 29.3 & 20.1 & 31.4 \\
\hline G & 1 June & 0.7 & 25.6 & 50 & 1018 & 1.9 & 371 & 5.1 & 54.8 & 8 & 875 & 974 & 26.7 & 37.6 & 27.4 & 38.7 \\
\hline G & 6 June & 1.5 & 23.2 & 66 & 1009 & 1.8 & 336 & 3.3 & 48.1 & 3 & 606 & 1009 & 23.2 & 32.1 & 25.3 & 37.1 \\
\hline $\mathbf{R}$ & 7 June & 1.9 & 21.9 & 55 & 1013 & 1.5 & 333 & 3.5 & 39.3 & 3 & 844 & 903 & 22 & 33 & 22.3 & 33.8 \\
\hline G & 21 June & 0.5 & 27.8 & 53 & 1017 & 1.5 & 322 & 4.5 & 55.2 & 1.8 & 856 & 904 & 29.5 & 39.6 & 29.9 & 40.1 \\
\hline $\mathbf{R}$ & 23 June & 1.1 & 27.8 & 60 & 1019 & 1.2 & 428 & 3.9 & 35.8 & 9 & 888 & 1035 & 28.8 & 40.2 & 29.7 & 41.9 \\
\hline G & 7 July & 0.8 & 29.7 & 39 & 1018 & 1.5 & 343 & 5.0 & 57.6 & 6 & 812 & 939 & 28 & 39.9 & 28.8 & 41.4 \\
\hline $\mathbf{R}$ & 14 July & 1.3 & 27.8 & 71 & 1009 & 1.5 & 343 & 5.3 & 35.2 & 13 & 836 & 1030 & 29.2 & 40.1 & 30.3 & 42.3 \\
\hline
\end{tabular}


Figure 4 shows the scatterplots of the significant correlations between heart rate and meteorological/pollutant data. A positive and significant correlation between the RR interval and atmospheric pressure was found $(\mathrm{R}=0.74, p$-value $=0.015)$ for running on the green route, whereas for running on red route, positive and significant correlations between the $R R$ interval and relative humidity $(R=0.54, p$-value $=0.046)$ and $C O$ concentration $(\mathrm{R}=0.56, p$-value $=0.036)$ were found. No significant correlations between heart rate and meteorological/pollutant data were found during walking for either the red or green routes.
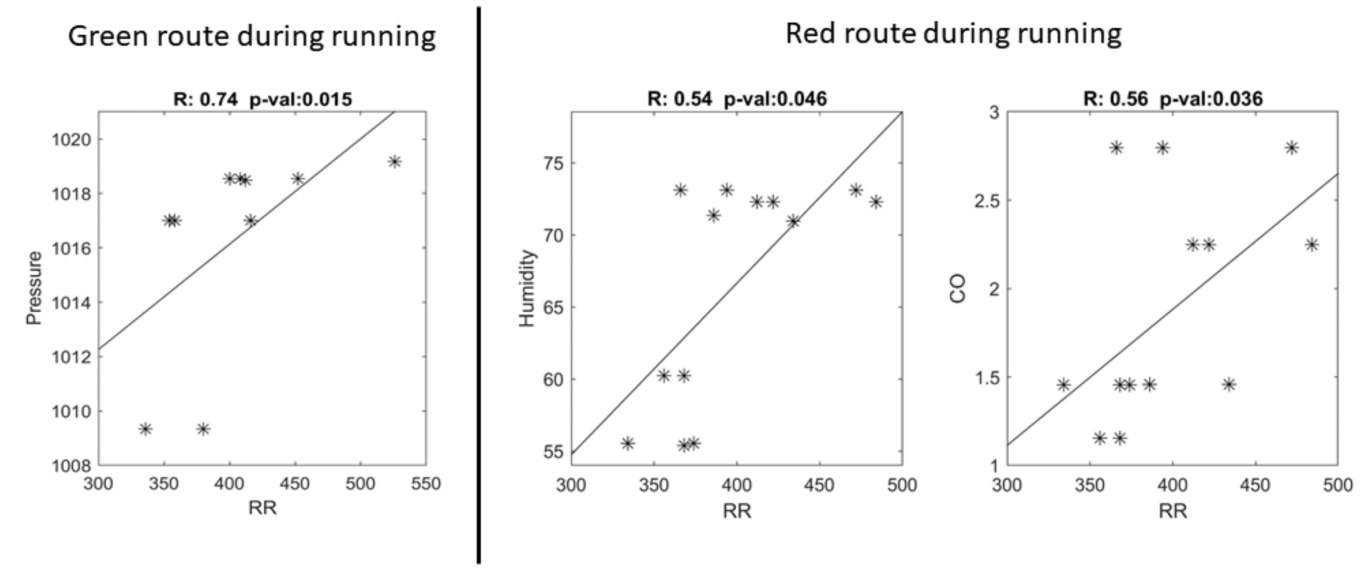

Figure 4. On the left is the scatterplot of the significant correlation between data during running for the green route ( $R R$ interval and atmospheric pressure), and on the right are the significant correlations between data during running for the red route ( $R R$ interval and relative humidity, and $\mathrm{RR}$ interval and CO concentration). The scatterplots report the lines of best fit, the Spearman's correlation coefficients (R), and associated $p$-values ( $p$-value). The RR interval is expressed in msec, atmospheric pressure in $\mathrm{hPa}$, relative humidity in percentage, and $\mathrm{CO}$ in $\mathrm{ppm}$.

Exploratory correlations between the derived cardiac parameters (heart rate variability indices) and the meteorological and pollutant data are reported in the Supplementary File S5: "Exploratory Statistical Analysis."

The pre-test normalized variables derived from the analysis of temperature perception and fatigue, such as "palpitations," "sweating," "general thermal sensation," "local thermal sensation" (of the face, back, anterior chest, abdomen, arms, hands, legs, and feet), and "effort level" increased significantly from walking to running ( $p$-value $<0.001$ for all variables). The increases did not change with the red or green routes. "Chills" was the only variable that remained stable between walking and running. The Supplementary File S4, "Questionnaire Data and Analysis", provides the complete rANOVA results.

The pollutant parameters generally revealed higher mean values of $\mathrm{CO}, \mathrm{CO}_{2}$, and $\mathrm{PM}_{2.5}$ for the red route than for the green route, during both the walking and running tests. A similar pattern was observed for the mean $\mathrm{HC}$ value during the running tests, whereas during walking the mean $\mathrm{HC}$ value was slightly higher for the green than the red route. Higher $\mathrm{O}_{3}$ values were generally detected for the green rather than the red tests. The parameters related to air quality $-\mathrm{CO}, \mathrm{CO}_{2}, \mathrm{O}_{3}$, and $\mathrm{PM}_{2.5}$-always remained below the reference thresholds indicated by the Regional Agency for Environmental Protection of Tuscany (ARPAT).

In terms of the microclimatic conditions, the days when the tests were conducted were characterized by clear or partly cloudy skies, with a solar radiation maximum of $756 \mathrm{watt} / \mathrm{mq}$ and a mean value of $623 \mathrm{watt} / \mathrm{mq}$ during the walk, and a $1072 \mathrm{watt} / \mathrm{mq}$ maximum and a mean value of $979 \mathrm{watt} / \mathrm{mq}$ during the run. The wind speed was weak during all test days, both for the walk and the run (below $2 \mathrm{~m} / \mathrm{s}$ ). The walking sessions were conducted early in the morning (from 8:00 to 10:00), and the air temperature ranged between $15.1^{\circ} \mathrm{C}$ ( 3 May 2017) and $27.7^{\circ} \mathrm{C}$ (7 July 2017), whereas the running test sessions were conducted later (from 10:00 to 12:00) when the air temperature values were higher, 
with peaks close to $30{ }^{\circ} \mathrm{C}$ on 7 July. The relative humidity was relatively high, with average values just over $60 \%$ during both the walking and running tests. Thus, the days selected to conduct the tests represented typical spring and summer microclimate conditions for the city of Pisa. These conditions often led to intense heat stress being observed in most of the tests, particularly during running. The UTCI confirmed average-to-moderate heat stress conditions during walking and strong heat stress conditions during running. Based on the average UTCI, $50 \%$ of the walking tests were carried out in strong heat stress conditions, about $27 \%$ in moderate heat stress conditions, and $23 \%$ with no thermal stress. About $77 \%$ of the running tests were carried out in strong heat stress conditions and the rest under moderate heat stress. The UTCI recorded mean values close to $32.5^{\circ} \mathrm{C}$ during the walk and $36{ }^{\circ} \mathrm{C}$ during the run. The thermal stress evaluated by the WBGT index for about $50 \%$ of the running tests exceeded the threshold of $27.9^{\circ} \mathrm{C}$, with values nearing $28^{\circ} \mathrm{C}$ during walking and $31^{\circ} \mathrm{C}$ during running.

Figures 5 and 6 show the concentrations of traffic-related pollutants (i.e., toluene and total xylenes (meta-, orto-, and para-xylene)) and metabolic and oxidative stress-associated VOCs (i.e., isoprene, acetone, 2-butanone, and 2-pentanone) detected and measured within the breath samples.
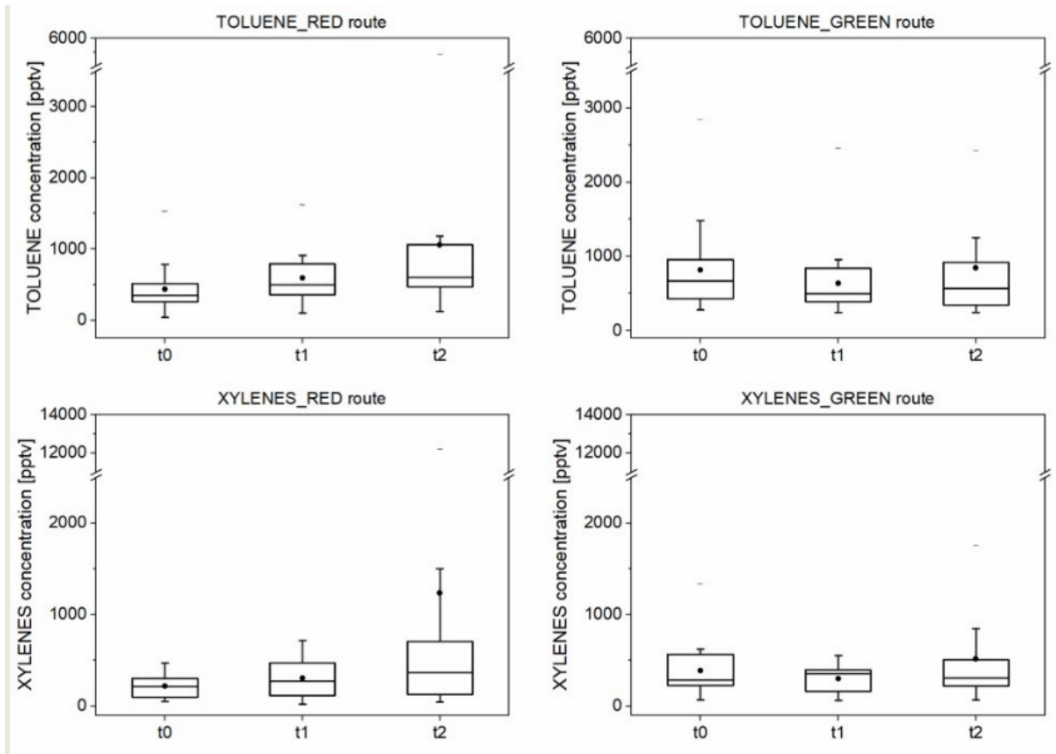

Figure 5. Box-plot of the concentration (expressed in pptv) of the traffic-related VOCs measured in the breath samples ( $n=15$ subjects) collected at the established times before the walk ( 0$)$, at its end (t1), and after the run ( $\mathrm{t} 2)$, during the tests on both green and red routes. Note: The box-plot shows the minimum, the 5th and the 25th percentiles, the median, the 75th and 95th percentiles, and the maximum values for each variable investigated. The dot inside the box shows the mean value. 


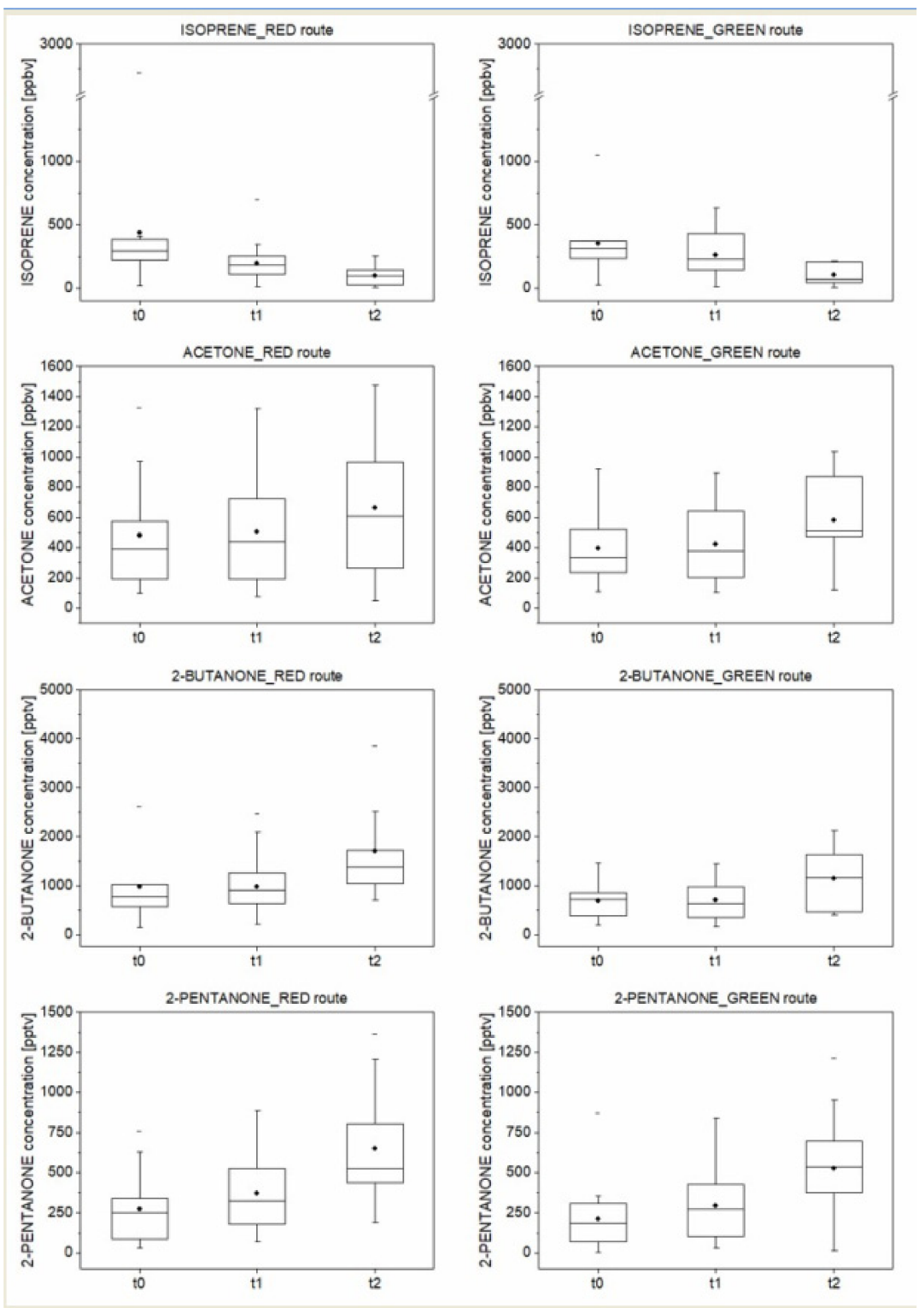

Figure 6. Box-plot of the concentration (expressed in pptv) of metabolic/oxidative stress-associated VOCs measured in the breath sample ( $n=15$ subjects) collected at the established times before the walk (t0), at its end ( 11$)$, and after the run ( 2 2), during the tests on both green and red routes. Note: The box-plot shows the minimum, the 5th, and the 25th percentiles, the median, the 75th, and 95th percentiles, and the maximum values for each variable investigated. The dot inside the box shows the mean value.

\section{Discussion}

The environmental sensor nodes were able to detect the concentrations of carbon monoxide $(\mathrm{CO})$, carbon dioxide $\left(\mathrm{CO}_{2}\right)$, unburned hydrocarbons $(\mathrm{HC})$, ozone $\left(\mathrm{O}_{3}\right)$, and fine particulate matter $\left(\mathrm{PM}_{2.5}\right)$, which were temporally matched with the activities of each volunteer. Higher concentrations of most of the pollutants monitored in the study were observed for the red route, which supports the assumption that urban parks and urban green areas in general can reduce concentrations of most pollutants, but also reveal increased $\mathrm{O}_{3}$ levels [31], which were also found in the monitored data, which revealed higher $\mathrm{O}_{3}$ values for the green rather than for the red route. Kuttler and Strassburger revealed an increase in $\mathrm{O}_{3}$ concentration in urban green areas in comparison to the nearby built up area during the summer [32]. Other studies conducted in Italy and in the Tuscany region have shown higher surface levels of $\mathrm{O}_{3}$ under the canopies of certain tree species [33] 
and a high potential for ozone formation in the main park of the city of Florence, which is linked to the presence of specific plants [34]. These elevated $\mathrm{O}_{3}$ levels result from the photochemical reaction of VOCs such as isoprene and monoterpenes, which can contribute to $\mathrm{O}_{3}$ formation under high solar radiation, elevated air temperature values, and weak wind speeds $[35,36]$. This phenomenon is more pronounced during the summer due to high solar radiation.

The microclimate conditions observed during the tests, and in particular those characterized by a WBGT threshold often exceeding $27.9{ }^{\circ} \mathrm{C}$ during the running tests, represents the limit beyond which an unacclimated subject must take care when performing competitive and long-duration sports activities, according to [37]. This WBGT-related heat stress risk threshold was also applied in a recent study [38] that aimed to estimate the impact of climate change, and therefore of high temperatures, on the potential performance of athletes during the Olympic Games in Tokyo that had been originally planned for the summer of 2020.

In this study, correlations between heart rate and the meteorological/pollutant data were only found during running conditions. A positive significant correlation between the RR interval and atmospheric pressure was found during the run on the green route. The reason for this relationship is not clear and it may have arisen by chance. Positive and significant correlations between the RR interval and relative humidity and CO concentration were found during the run on the red route. The increase in heart rates with relative humidity and $\mathrm{CO}$ concentration could be caused by the greater physical effort required due to environmental and pollution conditions, as they can affect physical activity. Interestingly, these correlations were not found for the green route, probably because of the effects of relative humidity and $\mathrm{CO}$ concentration on heart rate modulation. The levels of relative humidity and $\mathrm{CO}$ concentration for the green route sessions were lower on average than those of the red route sessions (see Table 2). Figure 4 also suggests a threshold mechanism for heart rate modulation with relative humidity and $\mathrm{CO}$ concentration.

From the analysis of temperature perception and fatigue recorded in the questionnaires, higher incidences of "palpitations," "sweating," "general thermal sensation," "local thermal sensation" (for the face, back, anterior chest, abdomen, arms, hands, legs, and feet), and "effort level" were reported in the post-run condition than in the post-walk condition. The specific routes did not appear to affect the perception of temperature and fatigue. Although the results are not significant, it is interesting to note that the post-run condition in the red route demonstrated higher values than in the green route for "palpitations," "sweating," "local thermal sensation" (for the face, back, abdomen, and legs), and "effort level." In general, these differences could be attributed to greater discomfort after the run for the red route than for the green route.

However, the results must all be interpreted with caution, because of the small sample size in the study and the large number of variables collected.

Thus, in this proof-of-concept study, breath analysis was used to evaluate the proposed personalized monitoring of exposure to environmental pollutants and of physical performance, through monitoring the variations of traffic-related pollutants (i.e., toluene and total xylenes (meta-, orto-, and para-xylene)) and other metabolic and oxidative stress-associated VOCs (i.e., isoprene, acetone, 2-butanone, and 2-pentanone) induced by performing physical activity along the red and green routes.

The results highlight that immediately after the walks and the runs in particular, the breath-exhaled toluene and total xylene concentrations were slightly higher $(p$-value $<0.05)$ than the pre-exercise levels for the red route (Figure 5), whereas breath concentrations of these compounds were not markedly different $(p$-value $>0.05)$ at each collection time for the green route (Figure 5). The increasing trend in the concentration of the traffic-related VOCs when exercising in polluted environments was not surprising, as the increase in minute ventilation during exercise increases proportionally to the quantity of inhaled air pollutants [9]. The breath-exhaled VOC levels were found to be highly variable from subject to subject, and breath concentrations after exercising on high-traffic routes were 
not statistically significantly higher than the low-traffic route levels. In fact, when breath composition was monitored for each volunteer, the concentration of traffic-related pollutants showed a more pronounced variation, confirming the usefulness of personalized monitoring, as reported elsewhere $[39,40]$.

Regardless of the route, increases in breath concentrations for the oxidative stressassociated VOCs (i.e., acetone, 2-butanone, and 2-pentanone) from the pre-exercise state were observed, whereas the isoprene breath concentrations showed a decreasing trend as the intensity of physical activity increased (from rest to the walk up to the run) (Figure 6). The increase of acetone observed after exercise could be due to the rapid catabolism occurring during exercise [41]. Senthilmohan et al. observed a slight increase in breath acetone values with physical exercise, reaching up to 100-1400 ppb [42]. Similar results from King et al. confirm the presence of fat catabolisms during exercise [23].

The significant decrease (i.e., by at least a factor of three) in breath isoprene levels after exercise may be due to the increase in both the respiratory rate and cardiac output. The increase in respiratory rate leads to a decrease in the tidal volume with a concomitant increase in the ventilation of the upper airway area $[43,44]$. This scenario affects compounds like isoprene that are mainly present in alveolar air. The occurrence of oxidative stress may explain the increased production of 2-butanone and 2-pentanone [19] and thus their increased breath levels.

\section{Conclusions}

In conclusion, as the present study was a pilot evaluation of the feasibility of multiparametric monitoring, further extensive studies are required to define and conduct other assessments by considering different days in different seasons of the year.

Supplementary Materials: The following are available online at https:/ / www.mdpi.com/1660-460 1/18/5/2432/s1, File S1: ICT infrastructure; File S2: Questionnaire; File S3: Subject Features; File S4 Questionnaire Data and Analysis; File S5: Exploratory Statistical Analysis

Author Contributions: Conceptualization, M.G.T., A.M. and M.M.; methodology, all authors; formal analysis, M.L., T.L., M.G.T., A.M. and M.M.; data curation, all authors; investigation, all authors; writing—original draft preparation, M.L., T.L., F.G.B., M.G.T., A.M. and M.M.; writing-review and editing, M.L., T.L., F.G.B., M.G.T., A.M. and M.M.; investigation, all authors; visualization, M.L., T.L., A.M. and M.M.; project administration, M.G.T., A.M. and M.M.; funding acquisition M.G.T., A.M. and M.M. All authors have read and agreed to the published version of the manuscript.

Funding: The SHE project was co-funded by the regional government in Tuscany (Italy) within the Call R\&D 2012 of the POR CREO FESR 2007-2013 regional programme.

Institutional Review Board Statement: The protocol was approved by the North West Area Ethics Committee of the Tuscany Region (CEAVNO, Autonomous Section of the Regional Ethics Committee for Clinical Trials, Resolution AOUP 838/2013).

Informed Consent Statement: Written informed consent has been obtained from the participants to publish this paper.

Data Availability Statement: The data presented in this study are available on request from the corresponding author.

Acknowledgments: The authors would like to thank Pisa's municipality, PISAMO, the project coordinator Infomobility srl, Digitech srl, Rigel Engineering srl, UNIFI-DISPAA, IFC-CNR, CNRIIT, and CNR-ISTI.

Conflicts of Interest: The authors declare that they have no actual or potential competing financial interests. 


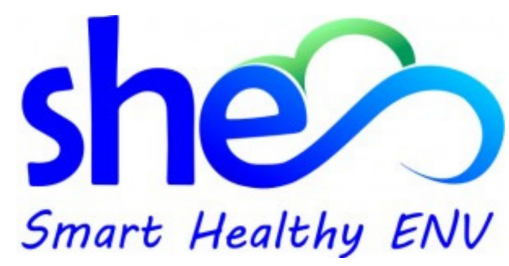

Infomobility: www.infomobility-italia.com (accessed on 19 January 2021)

Rigel: www.rigel.li.it (accessed on 19 January 2021)

Digitech: www.digitech.com (accessed on 19 January 2021)

Istituto di Scienza e Tecnologie dell'Informazione del CNR (CNR-ISTI): www.isti.cnr.it (accessed on 19 January 2021)

Istituto di Informatica e Telematica del CNR (CNR-IIT): www.iit.cnr.it (accessed on 19 January 2021) Istituto di Fisiologia Clinica del CNR (CNR-IFC): www.ifc.cnr.it (accessed on 19 January 2021)

Dipartimento di Scienze delle Produzioni Agro-alimentari e dell'Ambiente-Università degli Studi di Firenze (DISPAA—CIBIC): www.dispaa.unifi.it (accessed on 19 January 2021)

\section{References}

1. Sallis, J.F. Measuring Physical Activity Environments: A brief history. Am. J. Prev. Med. 2009, 36, S86-S92. [CrossRef] [PubMed]

2. O’Donovan, G.; Blazevich, A.J.; Boreham, C.; Cooper, A.R.; Crank, H.; Ekelund, U.; Fox, K.R.; Gately, P.J.; Giles-Corti, B.; Gill, J.M.R.; et al. The ABC of Physical Activity for Health: A consensus statement from the British Association of Sport and Exercise Sciences. J. Sports Sci. 2010, 28, 573-591. [CrossRef]

3. Thompson Coon, J.; Boddy, K.; Stein, K.; Whear, R.; Barton, J.; Depledge, M.H. Does Participating in Physical Activity in Outdoor Natural Environments Have a Greater Effect on Physical and Mental Wellbeing than Physical Activity Indoors? A Systematic Review. Environ. Sci. Technol. 2011, 45, 1761-1772. [CrossRef] [PubMed]

4. Fang, W.-T.; Ng, E.; Chang, M.-C. Physical Outdoor Activity versus Indoor Activity: Their Influence on Environmental Behaviors. Int. J. Environ. Res. Public Health 2017, 14, 797. [CrossRef] [PubMed]

5. Mytton, O.T.; Townsend, N.; Rutter, H.; Foster, C. Green space and physical activity: An observational study using Health Survey for England data. Health Place 2012, 18, 1034-1041. [CrossRef] [PubMed]

6. Schipperijn, J.; Bentsen, P.; Troelsen, J.; Toftager, M.; Stigsdotter, A.U.K. Associations between physical activity and characteristics of urban green space. Urban for. Urban Green. 2013, 12, 109-116. [CrossRef]

7. Brauer, M.; Freedman, G.; Frostad, J.; Van Donkelaar, A.; Martin, R.V.; Dentener, F.; Van Dingenen, R.; Estep, K.; Amini, H.; Apte, J.S.; et al. Ambient Air Pollution Exposure Estimation for the Global Burden of Disease 2013. Environ. Sci. Technol. 2016, 50, 79-88. [CrossRef]

8. West, J.J.; Cohen, A.; Dentener, F.; Brunekreef, B.; Zhu, T.; Armstrong, B.; Bell, M.L.; Brauer, M.; Carmichael, G.; Costa, D.L.; et al. What We Breathe Impacts Our Health: Improving Understanding of the Link between Air Pollution and Health. Environ. Sci. Technol. 2016, 50, 4895-4904. [CrossRef]

9. Carlisle, A.J.; Sharp, N.C. Exercise and outdoor ambient air pollution. Br. J. Sports Med. 2001, 35, 214-222. [CrossRef]

10. Kim, C.S.; Alexis, N.E.; Rappold, A.G.; Kehrl, H.; Hazucha, M.J.; Lay, J.C.; Schmitt, M.T.; Case, M.; Devlin, R.B.; Peden, D.B.; et al. Lung Function and Inflammatory Responses in Healthy Young Adults Exposed to 0.06 ppm Ozone for 6.6 Hours. Am. J. Respir. Crit. Care Med. 2011, 183, 1215-1221. [CrossRef]

11. Liu, S.-K.; Cai, S.; Chen, Y.; Xiao, B.; Chen, P.; Xiang, X.-D. The effect of pollutional haze on pulmonary function. J. Thorac. Dis. 2016, 8, E41-E56. [CrossRef] [PubMed]

12. Brunekreef, B.; Beelen, R.; Hoek, G.; Schouten, L.; Bausch-Goldbohm, S.; Fischer, P.; Armstrong, B.; Hughes, E.; Jerrett, M.; van den Brandt, P.V.D. Effects of long-term exposure to traffic-related air pollution on respiratory and cardiovascular mortality in the Netherlands: The NLCS-AIR study. Res. Rep. Health Eff. Inst. 2009, 71, 73-89.

13. De Maeyer, C.; Beckers, P.J.; Vrints, C.J.; Conraads, V.M. Exercise training in chronic heart failure. Ther. Adv. Chronic Dis. 2013, 4, 105-117. [CrossRef]

14. Gashaw, T.T.; Yitayal, A.A. Principal air pollutants and their effects on athletes health and performance: A critical review. Sci. Res. Essays 2019, 14, 44-52. [CrossRef]

15. Kippelen, P.; Fitch, K.D.; Anderson, S.D.; Bougault, V.; Boulet, L.-P.; Rundell, K.W.; Sue-Chu, M.; McKenzie, D.C. Respiratory health of elite athletes-Preventing airway injury: A critical review. Br. J. Sports Med. 2012, 46, 471-476. [CrossRef]

16. Rundell, K.W. Effect of air pollution on athlete health and performance. Br. J. Sports Med. 2012, 46, 407-412. [CrossRef]

17. Zhao, J.; Lorenzo, S.; An, N.; Feng, W.; Lai, L.; Cui, S. Effects of heat and different humidity levels on aerobic and anaerobic exercise performance in athletes. J. Exerc. Sci. Fit. 2013, 11, 35-41. [CrossRef]

18. Ghimenti, S.; Tabucchi, S.; Lomonaco, T.; Di Francesco, F.; Fuoco, R.; Onor, M.; Lenzi, S.; Trivella, M.G. Monitoring breath during oral glucose tolerance tests. J. Breath Res. 2013, 7, 017115. [CrossRef] 
19. Biagini, D.; Lomonaco, T.; Ghimenti, S.; Fusi, J.; Cerri, E.; De Angelis, F.; Bellagambi, F.G.; Oger, C.; Galano, J.M.; Bramanti, E.; et al. Saliva as a non-invasive tool for monitoring oxidative stress in swimmers athletes performing a VO2max cycle ergometer test. Talanta 2020, 216, 120979. [CrossRef]

20. Lomonaco, T.; Romani, A.; Ghimenti, S.; Biagini, D.; Bellagambi, F.G.; Onor, M.; Salvo, P.; Fuoco, R.; Di Francesco, F. Determination of carbonyl compounds in exhaled breath by on-sorbent derivatization coupled with thermal desorption and gas chromatographytandem mass spectrometry. J. Breath Res. 2018, 12, 046004. [CrossRef]

21. Kim, K.-H.; Jahan, S.A.; Kabir, E. A review of breath analysis for diagnosis of human health. TrAC Trends Anal. Chem. 2012, 33, 1-8. [CrossRef]

22. Lourenço, C.; Turner, C. Breath Analysis in Disease Diagnosis: Methodological Considerations and Applications. Metabolites 2014, 4, 465-498. [CrossRef] [PubMed]

23. King, J.; Kupferthaler, A.; Unterkofler, K.; Koc, H.; Teschl, S.; Teschl, G.; Miekisch, W.; Schubert, J.; Hinterhuber, H.; Amann, A. Isoprene and acetone concentration profiles during exercise on an ergometer. J. Breath Res. 2009, 3, 027006. [CrossRef]

24. Bacco, M.; Delmastro, F.; Ferro, E.; Gotta, A. Environmental Monitoring for Smart Cities. IEEE Sens. J. 2017, 17, 7767-7774. [CrossRef]

25. Minard, D.; Belding, H.S.; Kingston, J.R. Prevention of heat casualties. JAMA 1957, 165, 1813-1818. [CrossRef]

26. ISO 7243:2017. Ergonomics of the Thermal Environment-Assessment of Heat Stress Using the WBGT (Wet Bulb Globe Temperature) Index, 3rd ed.; ISO/TC 159/SC 5 Ergonomics of the Physical Environment; International Organization for Standardization: Geneva, Switzerland, 2017.

27. Fiala, D.; Havenith, G.; Broede, P.; Kampmann, B.; Jendritzky, G. UTCI-Fiala multi-node model of human heat transfer and temperature regulation. Int. J. Biometeorol. 2012, 56, 429-441. [CrossRef]

28. Havenith, G.; Fiala, D.; Błazejczyk, K.; Richards, M.; Broede, P.; Holmér, I.; Rintamaki, H.; Benshabat, Y.; Jendritzky, G. The UTCIclothing model. Int. J. Biometeorol. 2012, 56, 461-470. [CrossRef] [PubMed]

29. Ghimenti, S.; Lomonaco, T.; Bellagambi, F.G.; Tabucchi, S.; Onor, M.; Trivella, M.G.; Ceccarini, A.; Fuoco, R.; Di Francesco, F. Comparison of sampling bags for the analysis of volatile organic compounds in breath. J. Breath Res. 2015, 9, 047110. [CrossRef]

30. Ghimenti, S.; Tabucchi, S.; Bellagambi, F.G.; Lomonaco, T.; Onor, M.; Trivella, M.G.; Fuoco, R.; Di Francesco, F. Determination of sevoflurane and isopropyl alcohol in exhaled breath by thermal desorption gas chromatography-mass spectrometry for exposure assessment of hospital staff. J. Pharm. Biomed. Anal. 2015, 106, 218-223. [CrossRef]

31. Cohen, P.; Potchter, O.; Schnell, I. The impact of an urban park on air pollution and noise levels in the Mediterranean city of Tel-Aviv, Israel. Environ. Pollut. 2014, 195, 73-83. [CrossRef]

32. Kuttler, W.; Strassburger, A. Air quality measurements in urban green areas-A case study. Atmos. Environ. 1999, 33, 4101-4108. [CrossRef]

33. Fantozzi, F.; Monaci, F.; Blanuša, T.; Bargagli, R. Spatio-temporal variations of ozone and nitrogen dioxide concentrations under urban trees and in a nearby open area. Urban Clim. 2015, 12, 119-127. [CrossRef]

34. Paoletti, E.; Bardelli, T.; Giovannini, G.; Pecchioli, L. Air quality impact of an urban park over time. Procedia Environ. Sci. 2011, 4, 10-16. [CrossRef]

35. Donovan, R.G.; Stewart, H.E.; Owen, S.M.; MacKenzie, A.R.; Hewitt, C.N. Development and application of an Urban Tree Air Quality Score (UTAQS) using the Birmingham UK area as a case study. Environ. Sci. Technol. 2005, 39, 6730-6738. [CrossRef]

36. Loreto, F.; Bagnoli, F.; Fineschi, S. One species, many terpenes: Matching chemical and biological diversity. Trends Plant. Sci. 2009, 14, 416-420. [CrossRef]

37. Armstrong, L.E.; Casa, D.J.; Millard-Stafford, M.; Moran, D.S.; Pyne, S.W.; Roberts, W.O. American College of Sports Medicine position stand. Exertional Heat Illness during Training and Competition. Med. Sci. Sports Exerc. 2007, 39, 556-572. [CrossRef]

38. Kakamu, T.; Wada, K.; Smith, D.R.; Endo, S.; Fukushima, T. Preventing heat illness in the anticipated hot climate of the Tokyo 2020 Summer Olympic Games. Environ. Health Prev. Med. 2020, 22, 68. [CrossRef]

39. Biagini, D.; Lomonaco, T.; Ghimenti, S.; Bellagambi, F.G.; Onor, M.; Scali, M.C.; Barletta, V.; Marzilli, M.; Salvo, P.; Trivella, M.G.; et al. Determination of volatile organic compounds in exhaled breath of heart failure patients by needle trap micro-extraction coupled with gas chromatography-tandem mass spectrometry. J. Breath Res. 2017, 11, 047110. [CrossRef]

40. Williams, H.R.T.; Orchard, T.R. Volatile organic compounds in breath for monitoring IBD—Longitudinal studies are essential. Aliment. Pharmacol. Ther. 2017, 46, 371-372. [CrossRef]

41. Purdom, T.; Kravitz, L.; Dokladny, K.; Mermier, C. Understanding the factors that effect maximal fat oxidation. J. Int. Soc. Sports Nutr. 2018, 15, 1-10. [CrossRef]

42. Senthilmohan, S.; Milligan, D.; McEwan, M.; Freeman, C.; Wilson, P. Quantitative analysis of trace gases of breath during exercise using the new SIFT-MS technique. Redox Rep. 2000, 5, 151-153. [CrossRef]

43. Salvo, P.; Ferrari, C.; Persia, R.; Ghimenti, S.; Lomonaco, T.; Bellagambi, F.; Di Francesco, F. A dual mode breath sampler for the collection of the end-tidal and dead space fractions. Med. Eng. Phys. 2015, 37, 539-544. [CrossRef]

44. Lomonaco, T.; Salvo, P.; Ghimenti, S.; Biagini, D.; Bellagambi, F.; Fuoco, R.; Di Francesco, F. A breath sampling system assessing the influence of respiratory rate on exhaled breath composition. In Proceedings of the 37th Annual International Conference of the IEEE Engineering in Medicine and Biology Society (EMBC 2015), Milan, Italy, 25-29 August 2015; pp. 7618-7621. [CrossRef] 